\title{
Comparative studies on cell stimulatory, permeabilizing and toxic effects induced in sensitive and multidrug resistant fungal strains by amphotericin B (AMB) and $N$-methyl- $N$-D-fructosyl amphotericin B methyl ester (MFAME) ${ }^{\oplus \star}$
}

\author{
Joanna Szlinder-Richert ${ }^{1 凶}$, Barbara Cybulska ${ }^{1}$, Jolanta Grzybowska ${ }^{1}$, Edward \\ Borowski ${ }^{1}$ and Rajendra Prasad ${ }^{2}$ \\ ${ }^{1}$ Department of Pharmaceutical Technology and Biochemistry, Technical University of Gdańsk, \\ 80-952 Gdańsk, Poland; \\ ${ }^{2}$ School of Life Sciences, Jawaharlal Nehru University, New Delhi-110067, India
}

Received: 25 October, 1999

Key words: amphotericin B, amphotericin B derivative, antifungal action, multidrug resistance

\begin{abstract}
$N$-Methyl- $N$-D-fructosyl-amphotericin B methyl ester (MFAME) is a new derivative of amphotericin $\mathrm{B}$, which is characterised by low toxicity to mammalian cells and good solubility in water of its salts. The antifungal activity and effects of MFAME towards Candida albicans and Saccharomyces cerevisiae multidrug resistant MDR(+) and sensitive MDR(-) strains was compared with those of parent compound. The results obtained indicate that MDR(+) $S$. cerevisiae was sensitive to MFAME as well as to AMB. MFAME exhibited the same effects on fungal cells studied as parent antibiotic. The two antibiotics, depending on the dose applied induced cell stimulation, $\mathrm{K}^{+}$efflux, and/or had a toxic effect.
\end{abstract}

The major problem in antifungal chemotherapy is the lack of an effective and nontoxic drug for the treatment of systemic fungal infections. In the recent years a new threat

\footnotetext{
${ }^{\star}$ Presented at the $7^{\text {th }}$ International Symposium on Molecular Aspects of Chemotherapy, September 8-11, 1999, Gdańsk, Poland.

This work was supported in parts by grant 4 PO5F 03516 from the State Committee for Scientific Research (KBN, Poland) and by Chemical Faculty of Technical University of Gdańsk.

${ }^{\square}$ Correspondence to: Joanna Szlinder-Richert.

Abbreviations: $\mathrm{AMB}$, amphotericin B; c.f.u., colony forming units; $\mathrm{Me}_{2} \mathrm{SO}$, dimethyl sulfoxide; $\mathrm{MDR}(-)$, Saccharomyces cerevisiae JG 436 strain, in which the PDR5 gene encoding the main yeast drug extrusion pump was disrupted; MDR(+), S. cerevisiae PS 12-4 derived from JG 436 cells transformed with the $C D R 1$ gene, encoding the main $C a n d i d a$ albicans drug extrusion pump; MFAME, $N$-methyl- $N$-D-fructosyl amphotericin B methyl ester; MFC, minimal fungicidal concentration; MIC, minimal inhibitory concentration; YNB, yeast nitrogen base.
} 
emerged due to the appearance of multidrug resistant (MDR) fungal strains [1].

The polyene macrolide antibiotic amphotericin $\mathrm{B}$ (AMB) still remains the drug of choice in the clinical treatment of systemic mycoses. The main advantage of this drug is its broad antifungal spectrum and low frequency of clinical occurrence of fungal strains with developed specific resistance towards this compound. However, the low selective toxicity and poor water solubility seriously restrict clinical application of AMB.

Many efforts have been devoted to improvement of the pharmacological properties of AMB. This aim was only partially achieved by the development of new delivery systems [2]. A rational chemical modification of AMB seemed to be the most appropriate way to reach the goal. Strategy of designing modified AMB of low toxicity [3] and good water solubility [4], developed in our laboratory [5], led to the synthesis of a series of sterically hindered AMB derivatives. Perhaps the most interesting compound of this group is $N$-methyl$N$-D-fructosyl amphotericin B methyl ester (MFAME) [6] (Fig. 1). This compound forms parison with AMB it exhibits two orders of magnitude lower toxicity towards animal cells in vitro [7] and in vivo [6].

The mechanism of action of AMB is very complex and, in spite of intensive studies, still not completely understood [8]. Effects induced in fungal and mammalian cells by AMB are dependent on many factors such as: the antibiotic concentration, medium composition and other experimental conditions. The primary site of action of AMB is the cell membrane of sterol containing cells. The molecular basis of selective toxicity of AMB is it's higher affinity towards ergosterol (main sterol present in the fungal cell membrane) than to cholesterol (the principal sterol of mammalian cell membrane). The drug forms complexes with membrane sterols which associate into transmembrane channels through which free diffusion of many components essential for cell life occurs, leading to cell growth inhibition (cytostatic effect) or cell death (cytotoxic effect) [8].

Membrane permeabilization induced by AMB and by other polyene macrolides not always leads to a toxic effect. Moreover, in

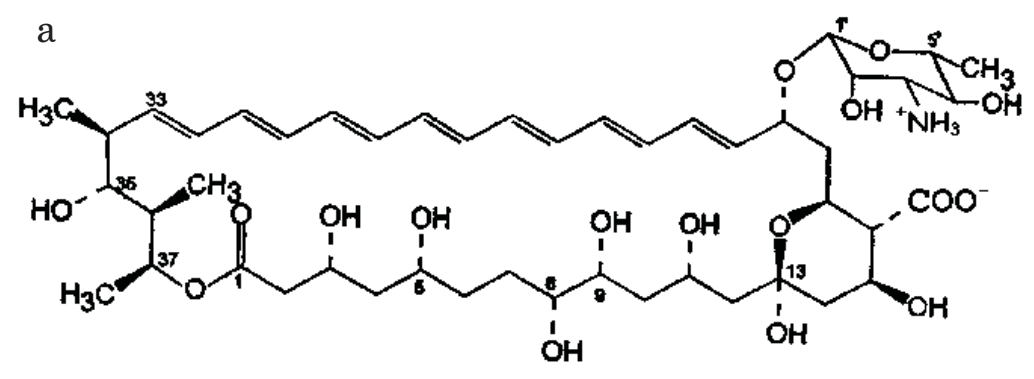

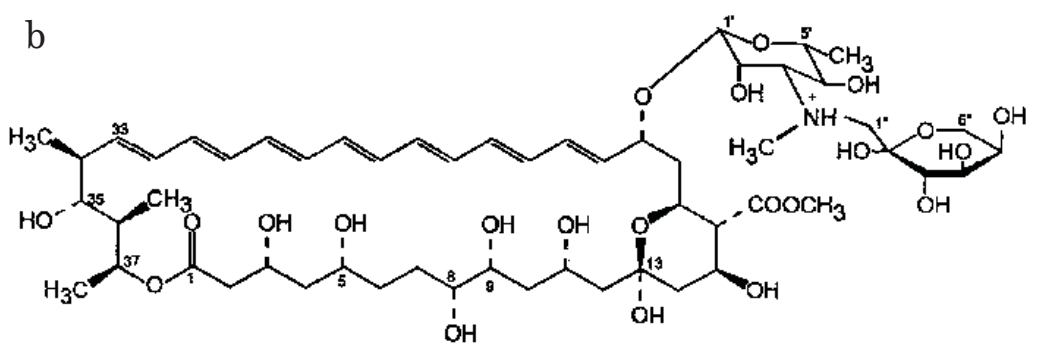

Figure 1. Structure of AMB (a) and MFAME (b).

perfectly water soluble salts, and retains the broad antifungal spectrum and potency of parent antibiotic. At the same time, in com- proper medium and experimental conditions, reversibility of the membrane damage was observed for fungal as well as mammalian cells 
[9-11]. In cells treated with AMB in subpermeabilizing concentration, several cellular functions were stimulated [12, 13]. Nevertheless, the molecular mechanism of action of MFAME is, as yet, very little known and is under investigation in our laboratory.

In this report we present comparative studies on the conditions in which: stimulation, permeabilization and toxic effect occur upon the action of AMB and MFAME on MDR(+) and MDR(-) fungal strains. The effect of AMB on multidrug resistant fungal strains so far, has not been extensively studied. It should be stressed that the ability of an antifungal agent to overcome the multidrug resistance is of primary importance, and the newly developed drug should be characterised with respect to this property.

\section{MATERIALS AND METHODS}

Cells and media. Strains: C. albicans ATCC 10261 was grown at $30^{\circ} \mathrm{C}$ in a medium containing: $1 \%$ bacto pepton (Difco), $2 \%$ glucose. Auxotrophic mutants: S. cerevisiae JG $436 \mathrm{MDR}(-)$ was grown at $30^{\circ} \mathrm{C}$ in a medium containing $1.7 \%$ YNB v/o amino-acids (Difco), $2 \%$ glucose, supplemented with methionine 20 $\mu \mathrm{g} / \mathrm{ml}$, leucine $40 \mu \mathrm{g} / \mathrm{ml}$, and uracil $30 \mu \mathrm{g} / \mathrm{ml}$; $S$. cerevisiae PS 12-4 MDR(+) with cloned $C D R 1$ multidrug resistance gene from $C$. albicans, was grown at $30^{\circ} \mathrm{C}$ in a medium containing $1.7 \%$ YNB v/o amino-acids, $2 \%$ glucose, supplemented with methionine 20 $\mu \mathrm{g} / \mathrm{ml}$, leucine $40 \mu \mathrm{g} / \mathrm{ml}$.

For MIC and MFC determination these media were supplemented with $0.1 \mathrm{M} \mathrm{KCl}$ or 0.1 $\mathrm{M} \mathrm{NaCl}$, respectively.

Polyene antibiotics. MFAME was synthesized in the Department of Pharmaceutical Technology and Biochemistry at the Technical University of Gdańsk. AMB was from Sigma. Purity of substances was determined spectrophotometrically $\left(\mathrm{A}_{1 \mathrm{~cm}}^{1 \%}=1600\right.$ at 382 $\mathrm{nm}$ for $\mathrm{AMB}$ and $\mathrm{A}_{1 \mathrm{~cm}}^{1 \%}=1100$ at $382 \mathrm{~nm}$ for MFAME-L-Asp). All concentrations given in the text are calculated for $100 \%$ pure compounds. The stock solutions of polyene macrolides $(1 \mathrm{mg} / \mathrm{ml})$ were prepared in dimethyl sulfoxide ( $\mathrm{Me}_{2} \mathrm{SO}$ ) (Sigma) just before use.

Determination of minimal inhibitory concentration (MIC) and minimal fungicidal concentration (MFC) of the antibiotics. MIC was determined by the serial dilution method in proper (cf. Cells and media) liquid medium containing $0.1 \mathrm{M} \mathrm{NaCl}$ or $0.1 \mathrm{M} \mathrm{KCl}$. Serial two-fold drug dilutions were prepared in $\mathrm{Me}_{2} \mathrm{SO} .10 \mu \mathrm{l}$ of the proper antibiotic solution was added to $2 \mathrm{ml}$ of cell suspension containing $10^{5}$ cells $/ \mathrm{ml}\left(\mathrm{A}_{660}\right.$ 0.01). The lowest concentration of the antibiotic yielding no growth in liquid medium after $18 \mathrm{~h}$ of incubation at $30^{\circ} \mathrm{C}$ was defined as MIC.

For MFC determination $10 \mu \mathrm{l}$ aliquots taken from samples in which cell growth was inhibited were plated on the proper solid agar media containing $0.1 \mathrm{M} \mathrm{NaCl}$ or $0.1 \mathrm{M} \mathrm{KCl}$. The lowest antibiotic concentration in which no cell colonies were observed after $48 \mathrm{~h}$ of incubation at $30^{\circ} \mathrm{C}$ was defind as MFC.

Determination of stimulatory effect. Cells from $18 \mathrm{~h}$ culture in liquid medium at $30^{\circ} \mathrm{C}$ were transferred to fresh medium and exposed to the assayed compound for $1 \mathrm{~h}$ at $30^{\circ} \mathrm{C}$ with shaking. Then cell suspension was diluted with distilled sterile water and plated on proper solid medium. After $48 \mathrm{~h}$ of incubation at $30^{\circ} \mathrm{C}$ colonies were counted. Stimulatory effect was expressed as increase in colony forming units (c.f.u.) in comparison to untreated cells.

Determination of $\boldsymbol{K}^{+}$efflux. $\mathrm{K}^{+}$efflux was recorded with $\mathrm{K}^{+}$sensitive electrode (Radiometer Copenhagen) introduced to cell suspension. Cells from $16 \mathrm{~h}$ cultures were harvested by centrifiguration and washed with cold $0.9 \%$ $\mathrm{NaCl}$. Cells were resuspended in $0.9 \% \mathrm{NaCl}$ at concentration $10^{8}$ cells $/ \mathrm{ml}\left(\mathrm{A}_{660} 1.0\right)$ and then antibiotic was added. Potassium released was 
expressed as a percentage of that obtained for the boiled control cell suspension.

\section{RESULTS}

\section{Stimulation}

The purpose of this experiment was to examine if $\mathrm{AMB}$ and its new derivative MFAME in subpermeabilizing concentration induce cell's growth stimulation. Determinations have been done for C. albicans ATCC 10261, S. cerevisiae JG $436 \mathrm{MDR}(-)$ and $S$. cerevisiae PS 12-4 MDR(+) (Fig. 2a and 2b, respectively). Stimulatory effect was observed for all strains studied and both antibiotics in concentrations below those leading to the permeabilizing effect. Maximal c.f.u. increase was in the range 18-30\%. Stimulatory concentration ranges were narrow in the case of $C$. albicans and wider for $S$. cerevisiae MDR(+) and MDR(-) strains. Maximal stimulatory effect in $C$. albicans was observed at the same concentration of the two antibiotics, whereas for $S$. cerevisiae MDR(+) and MDR(-) higher concentration of MFAME than of AMB was required (Table 1).

\section{Permeabilization}

The membrane permeability alteration induced by AMB and MFAME in the strains studied were measured by following $\mathrm{K}^{+}$efflux. The time course of $\mathrm{K}^{+}$release from $C$. albicans, S. cerevisiae MDR(-) and MDR(+) induced by AMB and MFAME are shown in Fig. $3 \mathrm{a}$ and $3 \mathrm{~b}$. Both antibiotics induced $\mathrm{K}^{+}$ efflux from all strains studied, but the strains differed in sensitivity. Potassium leak was observed above threshold concentration, which was $0.01 \mu \mathrm{g} / \mathrm{ml}$ in the case of $C$. albicans, and above $0.1 \mu \mathrm{g} / \mathrm{ml}$ for both strains of $S$. cerevisiae. The rate and extent of $\mathrm{K}^{+}$release were strongly dependent on antibiotics concentration. The experiments with $C$. albicans indicated that the fungicidal effect of either antibi-
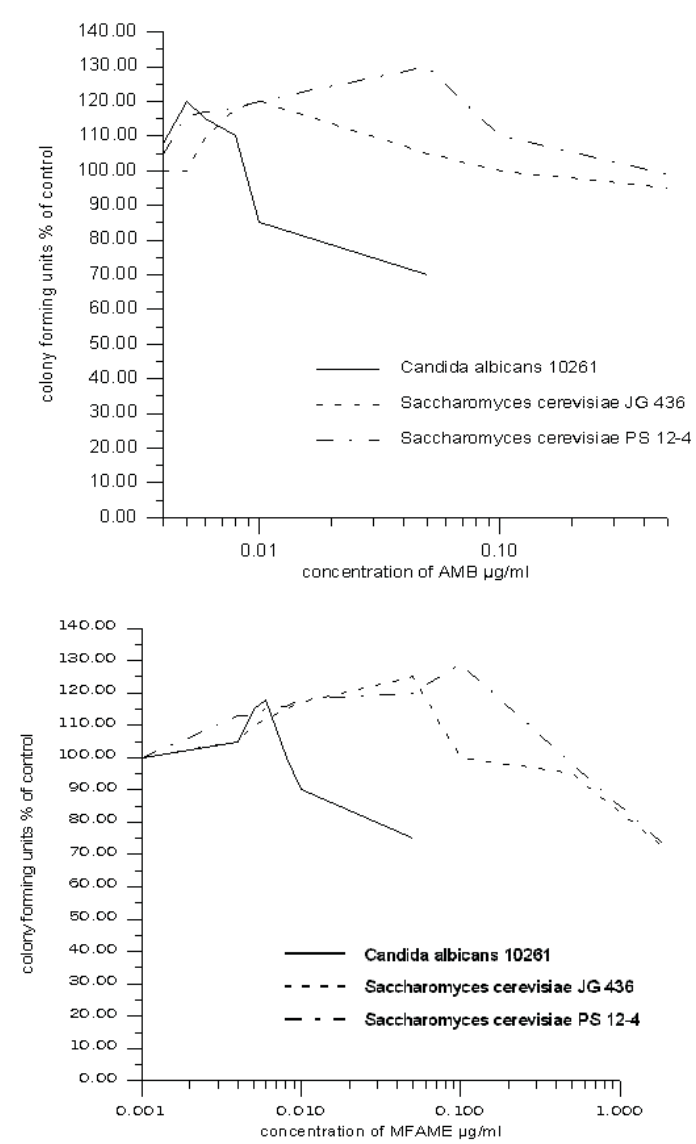

Figure 2. Effect of AMB (a) and MFAME (b) on the number of colonies formed by Candida albicans, Saccharomyces cerevisiae MDR(+) and MDR(-) on solid medium.

After $1 \mathrm{~h}$ of incubation with the antibiotic at $30^{\circ} \mathrm{C}$ cell suspension was properly diluted with distilled water and plated on solid medium. After $48 \mathrm{~h}$ of incubation at $30^{\circ} \mathrm{C}$ colonies were counted. Stimulatory effect was expressed as increase in colony forming units (c.f.u) in comparison to untreated cells.

otics was dependent on intracellular potassium level (Table 2). Cells were killed in one hour by antibiotic concentration causing almost $100 \%$ of $\mathrm{K}^{+}$efflux (AMB 1 and $5 \mu \mathrm{g} / \mathrm{ml}$, MFAME $5 \mu \mathrm{g} / \mathrm{ml}$ ) whereas with MFAME in concentration $1 \mu \mathrm{g} / \mathrm{ml}$, at which after $1 \mathrm{~h}$ of incubation potassium efflux was not complete, $25 \%$ of the cells in suspension remained alive and able to form colonies.

\section{Toxic effect}

The purpose of this experiment was to compare sensitivity of MDR(+) and MDR(-) fun- 
Table 1. Comparison of the stimulatory effect induced by MFAME and AMB on fungal cells

\begin{tabular}{llcc}
\hline Strains & Compounds & $\begin{array}{c}\text { Concentration } \\
(\mu \mathrm{g} / \mathrm{ml})\end{array}$ & $\begin{array}{c}\text { Max. c.f.u. increase } \\
(\%)\end{array}$ \\
\hline Candida albicans ATCC & AMB & 0.005 & 18 \\
10261 & MFAME & 0.006 & 20 \\
Saccharomyces cerevisiae & AMB & 0.01 & 22 \\
JG 436 MDR(-) & MFAME & 0.05 & 25 \\
Saccharomyces cerevisiae & AMB & 0.05 & 30 \\
PS 12-4 MDR(+) & MFAME & 0.1 & 30 \\
\hline
\end{tabular}

gal strains to AMB and MFAME, and to establish if antibiotic action is fungistatic or fungicidal. The influence of $\mathrm{Na}^{+}$and $\mathrm{K}^{+}$in the medium on antibiotic activity has been also examined. Results presented in Table 3 indicate that:
Salts of this compound with organic and inorganic acids are perfectly soluble in water. The compound retains the antifungal activity of parent antibiotic but is characterised by two orders of magnitude lower toxicity

Table 2. Correlation of antifungal effect of AMB and MFAME with the extent of intracellular potassium loss

\begin{tabular}{llcc}
\hline Strain & Compound & $\begin{array}{c}\text { Concentration } \\
(\mu \mathrm{g} / \mathrm{ml})\end{array}$ & $\begin{array}{c}\text { *Viable cells } \\
(\% \text { of control })\end{array}$ \\
\hline \multirow{2}{*}{ Candida albicans } & AMB & 1.0 & 0.066 \\
ATCC 10261 & AMB & 5.0 & 0.066 \\
& MFAME & 1.0 & 25.8 \\
& MFAME & 5.0 & 0.070 \\
\hline
\end{tabular}

antifungal effectivity of MFAME towards all three strains studied was almost the same as of that of the parent antibiotic. Both compounds were fungicidal, and MFC was only 2-5 fold higher than MIC. Presence of $\mathrm{K}^{+}$in the medium had no significant influence on cell sensivity to either antibiotic.

\section{DISCUSSION}

The purpose of our work was: 1) to compare the mode of action of MFAME and AMB on fungal cells, 2) to examine if AMB and the derivative are active against $\operatorname{MDR}(+)$ fungal strain.

MFAME is a rationally designed AMB derivative with improved pharmacological properties. against animal cells in in vitro experiments [7], and exhibits, in mice, acute $\mathrm{LD}_{50} 400$ $\mathrm{mg} / \mathrm{kg}$ as compared to $6 \mathrm{mg} / \mathrm{kg}$ for AMB [6]. These data suggest that the mechanisms of action of MFAME and AMB might be different. Our studies were carried out on pathogenic C. albicans ATCC 10261 and S. cerevisiae sensitive and with cloned multidrug resistance gene CDR1 from C. albicans. In this report the comparative studies on permeabilizing, fungistatic, fungicidal, and cell stimulatory effects induced by the two compounds in fungal cells are presented.

Our results indicate that action of MFAME, like that of AMB, is pleiotropic and causes in fungal cells several physiological effects distinguishable by their dose re- 
sponse. In low doses, which do not cause detectable $\mathrm{K}^{+}$efflux, MFAME induced cell stimulation expressed as an inrease in the number of colony-forming units in all three strains studied. Stimulatory action of MFAME and AMB was similar and was observed both in MDR(+) and MDR(-) strain. The mechanism of this phenomenon, described previously for $\mathrm{AMB}$ and C. albicans [12], is not clear but is attributed to an increase in plating efficiency. It was postulated that this was probably caused by AMB binding to fatty acids of the fungal cell wall. Such an explanation was based on similar results obtained for another antifungal drug, miconazol, for which an increase in plating efficiency was observed and was ascribed to its interaction with cell wall fatty acids. Stimulatory effect of AMB was also described for animal cells and bacteria [13, 14]. In mouse $\mathrm{L}$ cells, AMB at subpermeabilizing and subtoxic doses increased plating efficiency and stimulated the incorporation of precursors into DNA and RNA. Even very high doses of AMB are nontoxic for bacteria. However, in Escherichia coli a strong increase in colony forming ability was induced by AMB and MFAME. This observation seems to confirm that cell stimulation induced by AMB is not related to polyene-sterol interaction [14] as bacterial cell membrane is devoid of sterols.

Changes in membrane permeability are easily detected by $\mathrm{K}^{+}$leakage. For all strains studied and both compounds, rate and extent of $\mathrm{K}^{+}$release were strongly concentration dependent. Results obtained for C. albicans proved that the level of $\mathrm{K}^{+}$efflux influenced cell viability. We have found that MFAME as well as AMB exhibits fungicidal activity against MDR(+) and MDR(-) fungal strains in a concentration not much higher than minimal inhibitory concentration and presence of potassium ion in a medium had no significant influence on sensitivity of any of the strains studied. It has to be stressed that cytotoxic action is a very much desired feature of the antifungal drug especially in consideration of
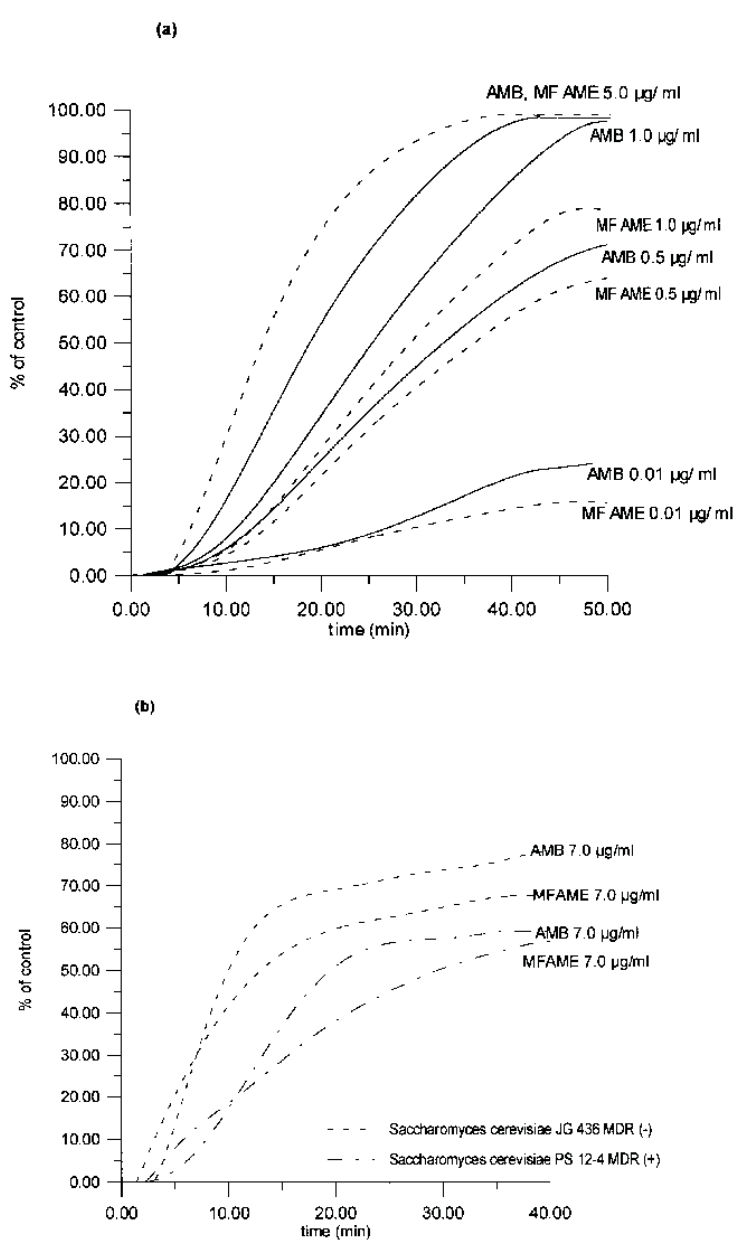

Figure 3. Kinetics of $\mathrm{K}^{+}$efflux from Candida albicans ATCC 10261 (a) and Saccharomyces cerevisiae MDR(+) and MDR(-) (b) induced by AMB and MFAME.

Cells were suspended in $0.9 \% \mathrm{NaCl}$ at concentration $10^{8}$ cells $/ \mathrm{ml}\left(\mathrm{A}_{660} 1.0\right)$ and the antibiotic was added. $\mathrm{K}^{+}$efflux was followed with $\mathrm{K}^{+}$sensitive electrode. Potassium released is expressed as a percentage of total potassium on the basis of boiled cell determinations.

it's clinical application for immunocompromised hosts.

The mechanism of toxic effect of AMB still remains unexplained. Some authors suggested that disturbance of the membrane permeability is not sufficient to induce toxic effect [16, 17]. The membrane lipids peroxidation was considered to be an additional factor, responsible for cell killing. In another work [18] relationship between the drug concentration dependent rate of $\mathrm{K}^{+}$release and 
Table 3. Sensitivity of Candida albicans 10261, MDR(+) and MDR(-) yeast strains to AMB and MFAME. Effect of $\mathrm{Na}^{+}$and $\mathrm{K}^{+}$on MIC i MFC

\begin{tabular}{llllll}
\hline Strains & Compounds & \multicolumn{2}{l}{$\mathrm{MIC}(\mu \mathrm{g} / \mathrm{ml})$} & \multicolumn{2}{l}{$\mathrm{MFC}(\mu \mathrm{g} / \mathrm{ml})$} \\
\hline Candida albicans & & $\mathrm{NaCl}$ & $\mathrm{KCl}$ & $\mathrm{NaCl}$ & $\mathrm{KCl}$ \\
ATCC 10261 & AMB & 0.05 & 0.1 & 0.1 & 0.2 \\
Saccharomyces cerevisiae & MFAME & 0.1 & 0.2 & 0.25 & 0.5 \\
PS 12-4 MDR(+) & MMB & 0.25 & 0.25 & 0.5 & 0.5 \\
Saccharomyces cerevisiae & AMB & 0.5 & 0.5 & 1.0 & 1.0 \\
JG 436 MDR(-) & MFAME & 0.5 & 0.1 & 0.5 & 0.5 \\
\hline
\end{tabular}

the concentration dependent rate of killing has been demonstrated.

Comparative studies of AMB and its derivative of low toxicity, MFAME, have evidenced that both compounds induce in fungal organisms comparable stimulatory, permeabilizing and fungicidal effects. These effects concern also multidrug resistant MDR(+) fungal strain examined. It is worth noting that the modification of AMB into MFAME did not abolish the essential property of AMB, i.e. the ability of the drug to overcome the multidrug resistance.

\section{R E F E R E N C E S}

1. Prasad, R., Krishna Murthy, S., Grupta, V. \& Prasad, R. (1995) Multiple drug resistance in Candida albicans. Acta Biochim. Polon. 42, 497-504.

2. Wasan, K.M. \& Lopez-Berestein, G. (1997) Diversity of lipid-based polyene formulations and their behaviour in biological systems. Eur. J. Microbiol. Infect. Dis. 16, 81-92.

3. Mazerski, J. \& Borowski, E. (1998) Molecular modelling in the rational design of some anti-tumor and antifungal agents. Task Quarterly 2, 511-550.

4. Mazerski, J., Grzybowska, J. \& Borowski, E. (1990) Influence of net charge on the aggregation and solubility behaviour of Amphotericin
B and its derivatives in aqueous media. Eur. Biophys. J. 18, 159.

5. Borowski, E. (1998) Molecular aspects of rational design of novel antifungal agents of low toxicity. Folia Pharmaceutica Universitatis Carolinae, XXIII (Suppl.) 12-19.

6. Grzybowska, J., Sowiński, P., Gumieniak, J., Zieniawa, T. \& Borowski, E. (1997) N-Methyl$N$-D-fructopyranosyloamphotericin B methyl ester, new amphotericin B derivative of low toxicity. J. Antibiotics 50, 709-711.

7. Bontemps-Gracz, M.M., Grzybowska, J., Supino, R. \& Borowski, E. (1999) In vitro evaluation of toxicity of amphotericin B derivatives towards mammalian cells. 7th International Symposium on Molecular Aspect of Chemotherapy, September, 1999, Gdańsk, Poland. Abstracts book; p. 159.

8. Bolard, J. (1986) How do the polyene macrolide antibiotics affect the cellular membrane properties? Biochim. Biophys. Acta. 864, 257304.

9. Borowski, E. \& Cybulska, B. (1967) Potassiumless death of Saccharomyces cerevisiae cells treated with $\mathrm{N}$-succinyl perimicin and the reversal fungicidal action of the antibiotic by potassium ions. Nature 213, 1034.

10. Malewicz, B. \& Borowski, E. (1979) Energy dependence and reversibility of membrane alter- 
ations induced by polyene macrolide antibiotics in Chlorella vulgaris. Nature 281, 80-82.

11. Malewicz, B., Jenkin, J.H. \& Borowski, E. (1981) Repair membrane alternation induced in baby hamster kidney cells by polyene antibiotics. Antimicrob. Agents Chemother. 19, 238-247.

12. Brajtburg, J., Elberg, S., Medoff, J. \& Kobayashi, G. (1981) Increase in colony forming units of $C$. albicans after treatment with polyene antibiotics. Antimicrob. Agents Chemother. 19, 199-200.

13. Brajtburg, J., Elberg, S., Medoff, J., Kobayashi, G., Schlessinger, D. \& Medoff, G. (1984) Stimulatory, permeabilizing, and toxic effect of amphotericin B on L cells. Antimicrob. Agents Chemother. 26, 892-897.

14. Mignini, F., Cybulska, B., Santoni, G., Giogi, M. \& Borowski, E. (1995) Polyene macrolides stimulate growth of $E$. coli and influence siderophores production. 5th International
Symposium on Molecular Aspects of Chemotherapy, August 1995, Gdańsk, Poland. Abstracts book; p. 99.

15. Malewicz, B., Howard, M., Jenkin, J.H. \& Borowski, E. (1980) Dissociation between the induction of potassium efflux and cytostatic activity of polyene macrolides in mammalian cells. Antimicrob. Agents Chemother. 17, 699-706.

16. Brajtburg, J., Powderly, W.G., Kobayashi, G.S. \& Medoff, G. (1990) Amphotericin B: current understanding of mechanism of action. Antimicrob. Agents Chemother. 34, 183-188.

17. Chen, W.C., Chou, D.-L. \& Feingold, D.S. (1978) Dissociation between ion permeability and lethal action of polyene antibiotics on Candida albicans. Antimicrob. Agents Chemother. 13, 914-917.

18. Beggs, W.H. (1994) Physicochemical cell damage in relation to lethal amphotericin B action. Antimicrob. Agents Chemother. 38, 363-364. 